\title{
Emotional Abuses of Slum Women by their Husbands in Kathmandu Valley
}

Manusha Paudel (M. Phil.)*

\begin{abstract}
Emotional abuse is a hardest form of abuse to recognize and globally it is a major public health problem. This study aims to explore the associated factors among slum married women in Kathmandu valley. It has used primary data from slum areas of Kathmandu valley and this study confined with married women only. Result showed more than two fifth (42\%) women's husband get angry if their wives talked with another male members either they are relatives or friends. The percent of emotional abuse was high where respondents did not attend school (33\%) than who attended school (21\%). Uniquely, study found that all alcohol user husbands insulted their wife in front of others and threatened or made worried. Despite that whose husbands did not use alcohol, their wives were not fallen on any types of emotional abuse. Additionally, quarrelling habit of husbands is also leading factor of emotional abuse. Findings of this study demonstrated that several factors are associated with emotional abuse including alcohol use, education, and occupation and battering habit. On the other hand, non-use of alcohol, high level of education, skilled occupation, and non-battering habit could protect women against emotional abuse by their husband. Therefore, interventions should focus on these issues for both men and women.
\end{abstract}

Key words: Married women, emotional abuse, slum \& domestic violence.

\section{Introduction}

Emotional abuse is one of the hardest forms of abuse to recognize. It is non-physical behavior or attitude that is design to control, subdue, punish or isolate another person through the use of humiliation or fear (Engel, 2002 \& Gordon 2018). A relationship is emotionally abusive when there is a consistent pattern of abusive words and bullying behaviors that wear down a person's self-esteem and undermine their mental health. Wife abuse is a complex phenomenon that has been investigated from many perspectives to determine causes and related factors (Martin, 1976).

*Ms. Paudel is a Lecturer at the Department of Population Studies, Patan Multiple Campus, TU, Lalitpur, Nepal. Email: manushapaudel@gmail.com 
High levels of conflict and violence have been found in marriages where one spouse dominates the other (Coleman \& Straus, 1986). The goal of emotional abuse is to control the victim by discrediting, isolating and silencing and at the end victim feels trapped (Gondolf, 2018). Some authors have reported that emotional abuse frequently coexists with physical abuse (Martin, 1976; Walker, 1984), which would support the idea that emotional abuse may be an important element in battering relationship. Similarly, some types of physical behavior can be considered as emotional abuse and examples include throwing objects, kicking on wall, shaking a finger or fist at the victim, driving recklessly while the victim is in the car, or threatening to destroy objects the victim values. Property damage is a form of emotional abuse considered 'Symbolic Violence' that results in serious psychological, social and economic costs (Marshal, 1996). Government of Nepal passed in 2008 Domestic Violence (offence and punishment) Act in May 2009; the act defines domestic violence as "any forms of physical, mental, sexual and economic abuse perpetrated by any person to the other person with whom he has a family relationship". The definition also applies to act of reprimand or emotional abuse (MoLJ, 2009).

NDHS, 2016 also defines emotional spousal violence: "say or do something to humiliate you in front of others, threaten to hurt or harm you or someone close to you, insult you or make you feel bad about yourself". It also applies in emotional abuse. Worldwide emotional abuse was a formerly neglected public health problem, which has gained more visibility over the past few decades. There is a high correlation between physical abuse and emotional abuse in batterer population (Gondolf et al., 2002) and verbal abuse early in a relationship predicts subsequent physical spousal abuse (Schumacher \& Leonare, 2005). So that, here is need to understand emotional abuse as a construct separate from physical abuse. However, none of these studies identified the factors associated with emotional abuse, which is an important step towards designing effective emotional abuse prevention programmes. Additionally, in patriarchal society like Nepal, women are often controlled by male family members. So that marital controlling behaviors can also be important in emotional abuse (NDHS, 2016).

The purpose of this study is to know the types of emotional abuse and its associated factors. Although the few studies on emotional abuse do exists, this types of abuse within intimate relationship among slum areas has not yet been undertaken in Nepal. This paper will be helpful to students who are associated with the component of reproductive health and likewise it will be fruitful to the programmers and policy makers to understand various factors influencing emotional abuse by husbands. 


\section{Objectives}

The main objective of the study is to provide the basic perception and its associated factors of emotional abuses in the study area. More specifically the objectives are: to explore the perceptions regarding emotional abuses of slum women by their husbands and to quantify the levels, demographic, social and economic factors and its association with different types of emotional abuses of slum women in the study area.

\section{Statement of the Problem}

Emotional abuse is a major neglected public health problem and it is directly connected with physical abuse. It is complex and we must study this issue separately. However in Nepal no systematic study on emotional abuse. Additionally, in patriarchal society like Nepal, women are often controlled by male family members. So that marital controlling behaviors can also be important in emotional abuse (NDHS, 2016). Our society has created an environment, where the society is tolerant of the abuser and is tolerant of the victim. This study has tried to determine and fulfill this gap.

\section{Justification}

Emotional abuse is a sensitive issue and none of these studies identified the factors associated with emotional abuse, which is an important step towards designing effective emotional abuse prevention programs. Although the few studies on emotional abuse do exists, this types of abuse within intimate relationship among slum areas has not yet been undertaken in Nepal. This paper will be helpful to students who are associated with the component of reproductive health and likewise it will be fruitful to the programmer and policy makers to understand various factors influencing emotional abuse by husbands.

\section{Methods}

This study used primary data from the five slum areas (Sankhamul, Khadipakha, Sinamangal, Balaju and Chabihil) of Kathmandu valley by using systematic random sampling technique. From each cluster fifty respondents were selected. In addition, qualitative information was collected by using in-depth and focus group discussion. The respondents were married female at the age of 15 years and above. Women, who were staying there for less than 6 months, were not included in this study. In addition, verbal informed consent was obtained from the participants before they enrolled in the study. 


\section{Interpretation of the Data and Results}

This study found that nearly half (46\%) of the women were aged 25-34 years while around one third (31\%) of them were aged 35 years or above. Slightly higher percentages of women $(47 \%)$ were primary education as compared to those no education $(29 \%)$. Majority of the respondents were Hindus (66\%) followed by Christian (30\%). Higher percentages of women were housewives (42\%) as compared to those who were involved in unskilled labor (34\%). The mean age of respondent was 30.35 years where, mean age at first marriage was 17.63 years (Table 1).

Table-1: Background characteristics of the respondents

\begin{tabular}{|l|c|c|}
\hline Background Characteristics & Number & Percent \\
\hline Age Group & & 22.8 \\
\hline Less than 25 years & 116 & 46.4 \\
\hline $25-34$ & 77 & 30.8 \\
\hline 35 or above & & \\
\hline Education & 72 & 28.8 \\
\hline No Education & 117 & 46.8 \\
\hline Primary & 61 & 24.4 \\
\hline Secondary or Above & & 66.4 \\
\hline Religion & 166 & 4.0 \\
\hline Hindu & 10 & 29.6 \\
\hline Buddhist & 74 & \\
\hline Christian & & 13.2 \\
\hline Types of Work & 33 & 34.0 \\
\hline Skilled Labor & 85 & 42.0 \\
\hline Unskilled Labor & 105 & 6.4 \\
\hline Housewife/Do not Earn & 16 & 3.6 \\
\hline Small Shop/Own Business & 9 & \\
\hline Social Workers & 2 & \\
\hline Dependent & 30.3 years & \\
\hline Mean Age of the Respondents & & \\
\hline Mean Age at First Marriage & & \\
\hline
\end{tabular}

Source: Field Survey, 2016

Table 1 illustrates that perception of husbands in relation with male members and their wives addresses as leading factor of emotional abuse. According to the responses of the 
respondents, more than two fifth (42\%) women's husbands got angry if their wife talked with another male members either they are relatives or friends.

Table-2: Perceptions regarding emotional abuses

\begin{tabular}{|l|c|c|}
\hline $\begin{array}{l}\text { Husbands Become Angry if Wife Talk with Male Member } \\
\text { (Outside of Family) }\end{array}$ & Number & Percent \\
\hline Yes & 105 & 42.0 \\
\hline No & 145 & 58.0 \\
\hline Total & 250 & 100.0 \\
\hline
\end{tabular}

Source: Field Survey, 2016

According to the results, if husbands had higher education, they took this issue normally and accepted it easily whereas if they had uneducated or lower level of education, problems occurred. Similarly, most of the FGD participants mentioned that around 90 per cent husband doubt on their wives if they talk with outside of family male members. They also added that sexual harassment is a type of emotional abuse; according to them, it means teasing and use ironical words to women. Likewise, 6 in 10 participants told that especially higher classes family have higher emotional abuse in their community but it remains as a hidden issue and they do not want to explore about it. In addition, one educated respondent said, "Married men feel proud if they controlled their wives and punished whenever they want. They always want to show controlling behavior in the community."

Table-3: Percentage distribution of respondents by the types of emotional abuses

\begin{tabular}{|l|c|c|c|}
\hline Types of emotional abuses & Yes & No & Total \\
\hline Have your husband ever dominated or insulted & 34.8 & 65.2 & 250 \\
\hline Have your husband ever insulted in front of others & 24.4 & 75.6 & 250 \\
\hline Have your husband ever threatened or made worried & 27.6 & 72.4 & 250 \\
\hline
\end{tabular}

Source: Field Survey, 2016

Table 3 illustrates that, slightly, less than 25 percent respondents reported that they had ever faced insult in front of others by their husbands whereas around 35 percent respondents reported that they had ever faced dominated or frustrated by their husbands. Similarly, around 28 percent reported that they had ever threatened or worried by their husbands.

In addition, the major causes of emotional abused were economic dependency and male superiority. From the in-depth interview researcher found that most of the abuses occurred by lack of education and lack of money with women as well. Similarly, from the 
focus group discussion, around 80 percent participants reported that these types of abused occurred because of lack of education and some of them focused on sexuality education or awareness campaign rather than literacy.

Table-4: Relationship between education and emotional abuse of respondents

\begin{tabular}{|l|c|c|c|}
\hline \multirow{2}{*}{ School Attendance } & \multicolumn{3}{|c|}{ Insulted in front of others by respondent's husband } \\
\cline { 2 - 4 } & Yes (\%) & No (\%) & Total Number \\
\hline Yes & 20.8 & 79.2 & 178 \\
\hline No & 33.3 & 66.7 & 72 \\
\hline Total $(\mathrm{N})$ & 61 & 189 & 250 \\
\hline
\end{tabular}

Source: Field Survey, 2016

Table 4 illustrates the association between education and emotional abuse namely insulted inform of others by respondent's husband. The percent of emotional abuse was high where respondents did not attend school. For instance, more than one third $(33 \%)$ not school attended women were insulted by their husband where the school attended insulted percent was one fifth $(21 \%)$.

Table-5: Relationship between occupation and types of emotional abuse of respondents

\begin{tabular}{|c|c|c|c|c|c|c|}
\hline \multirow{2}{*}{ Occupation } & \multicolumn{3}{|c|}{ Insulted in front of others $\mathrm{N}(\%)$} & \multicolumn{3}{|c|}{ Threatened or made worried N $(\%)$} \\
\hline & Yes $(\%)$ & No $(\%)$ & $\operatorname{Total}(\mathrm{N})$ & Yes $(\%)$ & No $(\%)$ & Total $(\mathrm{N})$ \\
\hline Skilled Labour & 15.2 & 84.8 & 33 & 12.1 & 87.9 & 33 \\
\hline Unskilled Labour & 43.5 & 56.5 & 85 & 49.4 & 50.6 & 85 \\
\hline Housewife & 16.2 & 83.8 & 105 & 20 & 80 & 105 \\
\hline Small Shop & 0 & 100 & 16 & 0 & 100 & 16 \\
\hline Social Worker & 0 & 100 & 9 & 0 & 100 & 9 \\
\hline Dependent & 100 & 0 & 1 & 100 & 0 & 2 \\
\hline Total & 24.4 & 75.6 & 250 & 27.6 & 72.4 & 250 \\
\hline
\end{tabular}

Source: Field Survey, 2016

Table 5 shows the relationship between occupation and types of emotional abuse namely insulted in front of others and threatened or make worried by respondent's husband. Studied showed that emotional abuse was higher among unskilled labour. In total unskilled labour, nearly half (44\%) were felt insult in front of others by their husband. Similarly, around half (49\%) respondents were threatened or made worried by their husband. On the other hand, emotional abuse was lower among skilled labour respondents. Study showed 
that only 15 percent skilled labour respondents felt insulted in front of others by their husband. Study also prevailed that respondents who were involved in social worker and had small shop had not felt on any types of emotional abuse. Besides those respondents who were dependents not able to work, had felt on all types of emotional abuse.

Table-6: Relationship between alcohol use of husbands and emotional abuse of respondents

\begin{tabular}{|l|c|c|c|c|c|c|}
\hline \multirow{2}{*}{$\begin{array}{l}\text { Alcohol Use of } \\
\text { Husband }\end{array}$} & \multicolumn{4}{|l|}{ Insulted in front of others } & \multicolumn{3}{l|}{ Threatened or made worried } \\
\cline { 2 - 7 } & Yes (\%) & No (\%) & Total (N) & Yes (\%) & No (\%) & Total (N) \\
\hline Yes & 29.5 & 70.5 & 207 & 33.3 & 66.7 & 207 \\
\hline No & 0 & 100 & 43 & 0 & 100 & 43 \\
\hline Total & 24.4 & 75.6 & 250 & 27.6 & 72.4 & 250 \\
\hline
\end{tabular}

Source: Field Survey, 2016

This study also found that, alcohol use of husband and types of emotional abuse are closely linked with each other. Table 6 illustrates that whose husbands had insulted their wife in front of others and threatened or made worried were only had alcohol users. Despite that whose husband had not used alcohol, their wives were not being affected on any types of emotional abuse.

Table-7: Relationship between Alcohol and Emotional Abuse of Respondents

\begin{tabular}{|l|c|c|c|c|c|c|}
\hline \multirow{2}{*}{$\begin{array}{l}\text { Alcohol Use of Re- } \\
\text { spondents }\end{array}$} & \multicolumn{3}{|l|}{ Insulted in front of others } & \multicolumn{3}{|c|}{ Threatened or made worried } \\
\cline { 2 - 7 } & Yes (\%) & No (\%) & Total (N) & Yes (\%) & No (\%) & Total (N) \\
\hline Yes & 50.4 & 49.6 & 113 & 41.6 & 58.4 & 113 \\
\hline No & 2.9 & 97.1 & 137 & 16.1 & 83.9 & 137 \\
\hline Total & 24.4 & 75.6 & 250 & 27.6 & 72.4 & 250 \\
\hline
\end{tabular}

Source: Field Survey, 2016.

Table 7 illustrates that more than half alcohol user respondents (50.4\%) had felt insult in front of others by their husband whereas the rate of non-alcohol users were only 3 percent. Similarly, more than two fifth $(42 \%)$ alcohol user women were threatened or made worried by their husband. On the other hand less than one fifth (16\%) non-alcohol users were threatened or made worried by their husband. 
Table 8: Relationship between husband's habit of quarrelling with others and emotional abuse of respondente

\begin{tabular}{|l|c|c|c|c|c|c|}
\hline \multirow{2}{*}{$\begin{array}{c}\text { Husband's Habit } \\
\text { of Quarrelling with } \\
\text { Others }\end{array}$} & \multicolumn{4}{|l|}{ Insulted in front of others } & \multicolumn{3}{l|}{ Threatened or made worried } \\
\cline { 2 - 7 } & Yes (\%) & No (\%) & Total (N) & Yes (\%) & No (\%) & Total (N) \\
\hline Yes & 32.5 & 67.5 & 126 & 34.1 & 65.9 & 126 \\
\hline No & 16.1 & 83.9 & 124 & 21 & 79 & 124 \\
\hline Total & 24.4 & 75.6 & 250 & 27.6 & 72.4 & 250 \\
\hline
\end{tabular}

Source: Field Survey, 2016

Study also found that quarrelling habit of husband was attached with emotional abuse. Table 8 illustrates that husband's habit of quarrelling with others had higher percentage on emotional abuse namely threatened or made worried $(34 \%)$ with their wife than who had had not habit of quarrelling with others $(21 \%)$.

\section{Discussion}

The perception regarding emotional abuse, the respondents asked the perception of their husbands in relation/discussion with other male members and respond that two fifth women's husbands got angry if their wife talked with another male member either they were relatives or friends. On the other hand, NDHS, 2016 showed that 24 percent husbands got jealous or angry if she talked to other men. The prevalence of emotional abuse among married women by their partner was 24 to 36 percent which is consistent from the finding from another study in Maldives which the prevalence of emotional abuse was 29 percent (GoM, 2005). Similarly from the study of WHO 2009, in Bhutan the emotional abuse was 23 percent. Our studies identifies that educated women were insulted or made frustrated by their husband was lower than uneducated women. Similarly NDHS 2016 shows uneducated emotional violence was 20 percent whereas SLC and above had only 7 percent. Heavy drinking patterns related to intimate partner violence and abuse. A research found that alcohol consumption is associated with increased risk of all forms of interpersonal violence and abuse (Jewkes, 2002). Similarly our study found that whose husband insulted their wife in front of others and threatened or make worried were only alcohol users. Our study also found that quarrelling habit of husband was connected with emotional abuse, in other word whose husbands had quarrelling habit with others had higher percentage of emotional abuse than non-quarrelling habit husband. Likewise, a study on American journal of public health found that, involvement in physical fights in the community and at work were positive relationship with abuse and violence within family (Abrahams, 2005). 


\section{Conclusion}

Emotional abuse is an attempt to control and emotional abuser does not use physical hitting, kicking, pinching, pushing or other physical form of harm. In this abuse, the perpetrator uses emotion as his or her weapon of choice. From the study, we found that here are many signs of an abusive relationship by partner. In study area, it is found that emotional abuses (doing frustrated, insulting in front of others and threaten or make worried) are common. Findings of this study demonstrated that several factors: educations, occupation, alcohol use, habit of quarrelling are associated with emotional abuse. Among them, alcohol consumption of husband is highly interrelated with the types of emotional abuse. It should provide a basis for using alcohol and its harmful effect for both women and their husband. In addition, level of education, skilled occupation, and non-battering habit could protect women against emotional abuse by their husband. Therefore, interventions should focus on these issues for both men and women.

\section{References}

Abrahams, N. (2005). Men's use of violence against women: A study of working men in Cape Towns South Africa. University of Cape Town, South Africa

Coaleman, D. \& Straus, M. A. (1986). Marital power, conflict and violence in a nationally representative sample of Americans. Journal of Violence and Victims. 1(2), 141-157.

Engel, B. (2002). The emotionally abusive relationship: How to stop being abused and how to stop abusing. New Jersey: John Wiley and Sons.

Gondolf, E. W., Heckert, D. A. \& Kimmel, C. M. (2002). Non physical abuse among batterer program participants. Journal of Family Violence, 17, 293-314.

Gondolf, E. W. (2018). Theoretical and research support for the duluth model: A reply to Dutton and Corvo. Aggression and Violent Behaviour, 9 (6), 644-657.

Government of Maldives (GoM). (2005). The Maldives study on women's health and live experiences. Initial results on prevalence, health outcomes and women's responses to violence. Ministry of Gender and Family, Maldives.

Jewkes, R. (2002). Intimate partner violence: Cause and prevention. The Lancet, 359(9315), 1423-1429.

Marshall, L. (1996). Psychological abuse of women: Six distinct lusters. Journal of Family Violence. 11(4), 379-409.

Martin, D. (1976). Battered wives, national library of medicine. San Francisco, California, United States.

Ministry of Health and Population (MoHP). (2017). Nepal demographic and health survey 2016. 
Kathmandu: Ministry of Health and Population, New ERA, and ICF International, Nepal.

Ministry of Law and Justice (MoLJ). (2009). Domestic violence act, 2009. http://www. lawcommission.gov.np/en/documents/domestic-violence-crime-and-punishmentact-2066-2009.pdf

Schumacher, J. A., \& Leonard, K. E. (2005). Husbands' and wives' marital adjustment, verbal aggression and physical aggression in early marriage. Journal of Consulting and Clinical Psychology. 73, 28-37.

Sherri, G. (2018). How to identify and cope with emotional abuse. https://www.verywellmind. com/identify-and-cope-with-emotional-abuse-4/56673.

Walker, L. E. (1984). The battered woman syndrome. New York: Springer Publishing Company, United States. 